\title{
diffusion-fundarnentals.org
}

The Open-Access Journal for the Basic Principles of Diffusion Theory, Experiment and Application

\section{Diffusion in Solid-Earth Systems}

\author{
E. Bruce Watson \\ Department of Earth \& Environmental Sciences, Rensselaer Polytechnic Institute, Troy, \\ NY 12180, USA, E-Mail: watsoe@rpi.edu
}

\section{Introduction}

The term "solid Earth" encompasses our entire planet except the atmosphere and oceans. To non-experts, this term might convey the impression of a static, frozen planet, but in fact the solid Earth is remarkably dynamic on timescales ranging from minutes to millions of years. Earth's interior is sufficiently hot to support the localized existence of various fluids-including supercritical $\mathrm{C}-\mathrm{O}-\mathrm{H}$ fluids, molten silicate and molten Fe-Ni alloys. It is also hot enough at depth to "activate" solid-state diffusion in a wide variety of crystalline phases, ranging from biogenic carbonates used as climate proxies to rareelement minerals exploited for radiometric dating of geological materials and events.

Interest in diffusion among geoscientists traces back to the early 20th century, but the phenomenon became especially important in the 1960s when geochemists recognized the possibility that open-system behavior could compromise parent/daughter isotope ratios used for age determinations. Experimental studies of diffusion in Earth materials (solids, liquids, supercritical fluids) blossomed in the 1970s and 80s and have proliferated into the $21^{\text {st }}$ century. Today, the characterization of diffusion constants and their use in models of Earth-system dynamics is a vital pursuit in solid-Earth geochemistry. Modern experimental characterizations of diffusants in Earth materials involve a variety of experimental approaches and exploit established analytical technologies (SIMS, NRA, RBS, LA-ICP/MS). Molecular-scale simulation approaches are now gaining a foothold as well, but in general these cannot yet provide stand-alone information.

\section{Illustrative examples}

Known Arrhenius laws for natural materials span a vast range, from ultra-fast diffusion of $\mathrm{SiO}_{2}$ solute in supercritical $\mathrm{H}_{2} \mathrm{O}\left(\mathrm{D} \sim 10^{-7} \mathrm{~m}^{2} \cdot \mathrm{s}^{-1}\right.$ at $900^{\circ} \mathrm{C}$ ) to extraordinarily slow diffusion of tetravalent cations in Earth's oldest materials: 4.4 billionyear-old zircons $\left(\mathrm{ZrSiO}_{4}\right)$ from Western Australia's Jack Hills (D $10^{-20} \mathrm{~m}^{2} \cdot \mathrm{s}^{-1}$ at $1600^{\circ} \mathrm{C}$; see Fig. 1$)$. Whether fast or slow, knowledge of diffusion constants is essential to constrain the time- and length scales

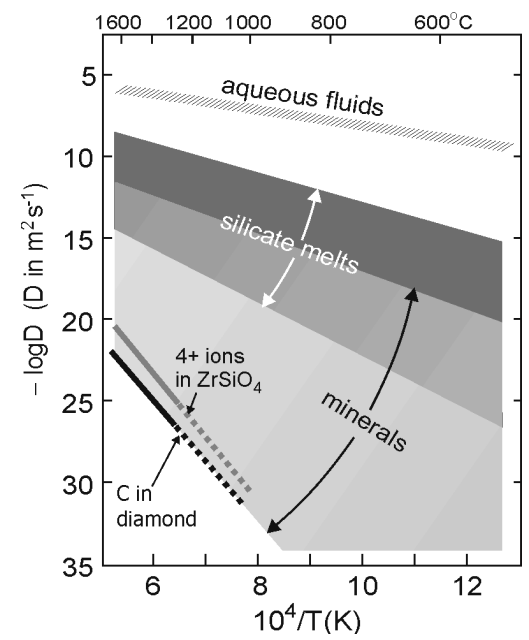


of chemical transport in Earth systems. In some instances, diffusion in crystals at very small length scales ( $\sim$ one nanometer) can have important geochemical implications. It is well known, for example, that the equilibrium structure and composition of the nearsurface region of a crystal - the outermost few nanometers - is slightly different from the bulk lattice due to relaxation of atoms from their lattice positions in the bulk crystal. Rapid crystal growth can result in "capture" of the anomalous surface composition if diffusion in the crystal is too slow to maintain equilibrium behind the advancing interface $[1,2]$.

The other end of the spectrum of plausible diffusive length scales in the Earth is on the order of 10 kilometers. Diffusion through interconnected supercritical fluid or along grain boundaries in rocks at high temperatures $\left(>1000^{\circ} \mathrm{C}\right)$ can operate at vast distances because of the sustained stability of supercritical fluids and the availability of huge expanses of time - millions or even billions of years.

Broadly speaking, geochemists use diffusion data in one of two ways. On the one hand, well-characterized diffusion laws are used as input for forward models of geochemical transport, which are then tested against observations from natural materials. Consistency of model with observation is taken as understanding, but it is important to bear in mind that this approach does not necessarily yield unique results. For this reason, inverse modeling strategies are developed whenever possible to enable definitive reconstruction of the time-temperature histories of Earth systems and time-integrated transport effects.

\section{Conclusions}

Knowledge of diffusion in solid-Earth systems is vital to understanding mass transport in and on our planet at a variety of spatial and temporal scales. Experimental measurements spanning considerable P-T space underpin models of transport in the Earth, but there is much more to learn through integration of experiments with molecular modeling and simulation.

\section{References}

[1] E.B. Watson, Y. Liang, American Mineralogist 80 (1995) 1170-1187.

[2] E.B. Watson, Geochimica et Cosmochimica Acta 68 (2004) 1473-1488. 